\title{
BMJ Open Stroboscopic light effects during electronic dance music festivals and photosensitive epilepsy: a cohort study and case report
}

\author{
Newel Salet, ${ }^{1}$ Marieke Visser, ${ }^{2}$ Cornelis Stam, ${ }^{3}$ Yvo M Smulders ${ }^{4}$
}

To cite: Salet N, Visser M, Stam C, et al. Stroboscopic light effects during electronic dance music festivals and photosensitive epilepsy: a cohort study and case report. BMJ Open 2019;9:e023442. doi:10.1136/ bmjopen-2018-023442

- Prepublication history and additional material for this paper are available online. To view please visit the journal (http:// dx.doi.org/10.1136/bmjopen2018-023442).

Received 16 April 2018

Revised 8 April 2019

Accepted 17 April 2019

D Check for updates

(c) Author(s) (or their employer(s)) 2019. Re-use permitted under CC BY-NC. No commercial re-use. See rights and permissions. Published by BMJ.

${ }^{1}$ Department of Internal Medicine, VU Medisch Centrum, Amsterdam, Noord-Holland, The Netherlands

${ }^{2}$ Neurology, VUmc University Medical Centre, Amsterdam, The Netherlands

${ }^{3}$ Department of Clinical Neurophysiology and MEG Center, VU University Medical Center, Amsterdam, The Netherlands

${ }^{4}$ Internal Medicine, VUmc University Medical Centre, Amsterdam, The Netherlands

Correspondence to

Newel Salet; n.salet@vumc.nl

\section{ABSTRACT}

Objectives Electronic dance music (EDM) concerts are becoming increasingly popular. Strong stroboscopic light effects are commonly part of these shows, and may provoke seizures in individuals with photosensitive epilepsy. This study aims to examine the risk of epileptic seizures during EDM concerts.

Setting 28 EDM concerts taking place in The Netherlands. Participants We describe a young man who experienced a seizure during an EDM concert, and who later showed a positive electroencephalographic provocation test during exposure to video footage of the same concert. Subsequently, we performed a cohort study of 400343 visitors to EDM concerts, divided in those exposed (concert occurring in darkness) versus unexposed (concert in daylight) to stroboscopic light effects.

Results In total, 400343 EDM concert visitors were included: 241543 (representing 2222196 person hours) in the exposed group and 158800 (representing 2334 360 person hours) in the control group. The incidence density ratio of epileptic seizures in exposed versus unexposed individuals was $3.5(95 \% \mathrm{Cl}: 1.7$ to 7.8 ; $p<0.0005)$. Less than one-third of cases occurred during use of ecstasy or similar stimulant drugs.

Conclusion Stroboscopic light effects during EDM concerts occurring in darkness probably more than triple the risk of epileptic seizures. Concert organisers and audience should warn against the risk of seizures and promote precautionary measures in susceptible individuals.

\section{INTRODUCTION}

Electronic dance music (EDM) is an annually increasing enterprise, attracting many thousands of visitors and grossing a worldwide revenue of 5.7 billion dollars a year. ${ }^{1}$ The increasing popularity of EDM festivals is accompanied by a similar increase in the number of young people exposed not only to loud music, but also intense stroboscopic light effects. Such light effects, particularly in the range of $15-25 \mathrm{~Hz}$, are known for their potential to evoke seizures, especially in young, sleep-deprived individuals who have (latent) photosensitive epilepsy (PSE). ${ }^{2}$
Strengths and limitations of this study

- Presently, no information is available about photosensitive epilepsy (PSE) incidence at electronic dance music (EDM) festivals.

- The comprehensive number of people in this database allows for meaningful comparison between groups.

- It is likely/probable that this study underdiagnoses PSE at EDM festivals.

- There is little data available about people who did not require medical attention during EDM festivals.

Whether EDM concerts are indeed associated with risk of PSE has never been studied and, perhaps as a consequence, EDM concert organisers do not routinely warn visitors of such risks. Literature has shown that exposure to stroboscopic effects in the public domain can lead to seizures, for example, report cases of epilepsy in discotheques, where many youngsters experience their first exposure to stroboscopic light effects. ${ }^{3}$ Also, the epileptic 'outbreak' following after television airing of an episode of Pokémon in Japan being a well-known example. ${ }^{4}$ The pathophysiology underlying these photo paroxysmal events supports our hypotheses that the incidence of seizures at EDM festivals might be significantly elevated due to the use of stroboscopic light effects, resulting in an association between EDM festivals and enhanced seizure risk. $^{5}$

This hypothesised risk will probably be higher in comparison to the general population given the age-dependent nature of PSE. ${ }^{67}$ We first present a case of a young man who collapsed during an EDM festival, and showed during a later performed EEG examination epileptiform discharges in the electroencephalogram during exposure to video footage of the same concert. In addition, a cohort study was conducted to address the 
incidence of PSE resulting from stroboscopic light effects during EMD festivals.

\section{CASE REPORT}

During a nightly Amsterdam indoor EDM festival, a 20-year-old man spectator suddenly collapsed. Just prior to collapsing, this individual was looking at the stage and reported having discomforting 'aura-like' experience. This was later confirmed by his accompanying friends. Bystanders in the audience described typical features of a tonic-clonic seizure, accompanied by tongue bite and urine loss. The duration of the seizure was a few minutes, after which he slowly regained consciousness, but remained drowsy and disoriented.

He was brought to the emergency room of our hospital, by which time he had fully regained consciousness and composure. He denied use of alcohol or drugs, nor did he use any medication. He did not report a history of (epileptic) seizures. When asked about preseizure symptoms, he remembered an urge to turn his eyes away from the strong stroboscopic light effects coming from the stage in front of him, because they elicited what he referred to as discomforting sensations. We hypothesise these sensations possibly represented aura preceding PSE. ${ }^{8}$ A brief neurological examination was normal and he was discharged and scheduled for later outpatient evaluation.

A few weeks later, after overnight sleep deprivation, the patient was submitted to routine electroencephalography (EEG) diagnostics, with EEG recording during stroboscopic stimulation. Coincidentally, one of the authors of this manuscript (YMS) was also present at the same concert, and had made a video recording with his cell phone around the same time the patient had seized elsewhere in the audience. The test was therefore expanded by exposing the patient to this video showing strong stroboscopic light effects.

The EEG was normal at baseline and during hyperventilation. Stroboscopic light effects throughout the $14-25 \mathrm{~Hz}$ range elicited generalised epileptiform discharges (spike waves) with a frequency of $>3 \mathrm{~Hz}$, accompanied by sensation the patient recognised from the concert. During exposure to the video (online supplementary video), similar peak wave complexes and sensations occurred, supporting the diagnosis of PSE. A still from the recording is displayed in figure 1 .

\section{METHODS}

The cohort study was designed, executed and described in accordance with the Strengthening the Reporting of Observational Studies in Epidemiology statement. ${ }^{9}$ The study domain consisted of visitors to EDM festivals in The Netherlands in the year 2015. All such festivals use stroboscopic light effects. To clarify the role of these light effects in causing seizures, the cohort was divided in exposed versus unexposed (or, in fact, less exposed) participants by distinguishing festivals taking place in the dark (indoors or during night-time; exposed) versus those taking place in daylight (unexposed). Figure 2 summarises the study design, group distribution and outcome parameters in further detail. The study was approved by the hospital's medical ethics committee.

Participants consisted of all visitors of EDM concerts taking place at various locations in The Netherlands between 1 January 2015 and 31 December 2015. The Netherlands has a high density of EDM festivals due to the fact that many of the world's top disc jockeys are Dutch. Festivals without stroboscopic light effects were excluded. Visual evidence to determine if a festival used stroboscopic light effects is widely available on social media and video-stream websites, and thus the presence of said light effects was verified.

The primary outcome was the incidence density of epileptic seizures. Incidents were registered as such if an emergency care professional on site determined one or several subsequent 'epileptic seizures' as the most likely diagnosis, based on the combination of witness reports (eg, sudden onset, loss of consciousness, muscle contractions) and physical findings (eg, lateral tongue bite, urinary incontinence). Covariables registered for the seizure cases included gender and age.

Other variables collected included the total number of medical assistances, medical assistance for suspected ecstasy use (self-reported of likely because of symptoms),
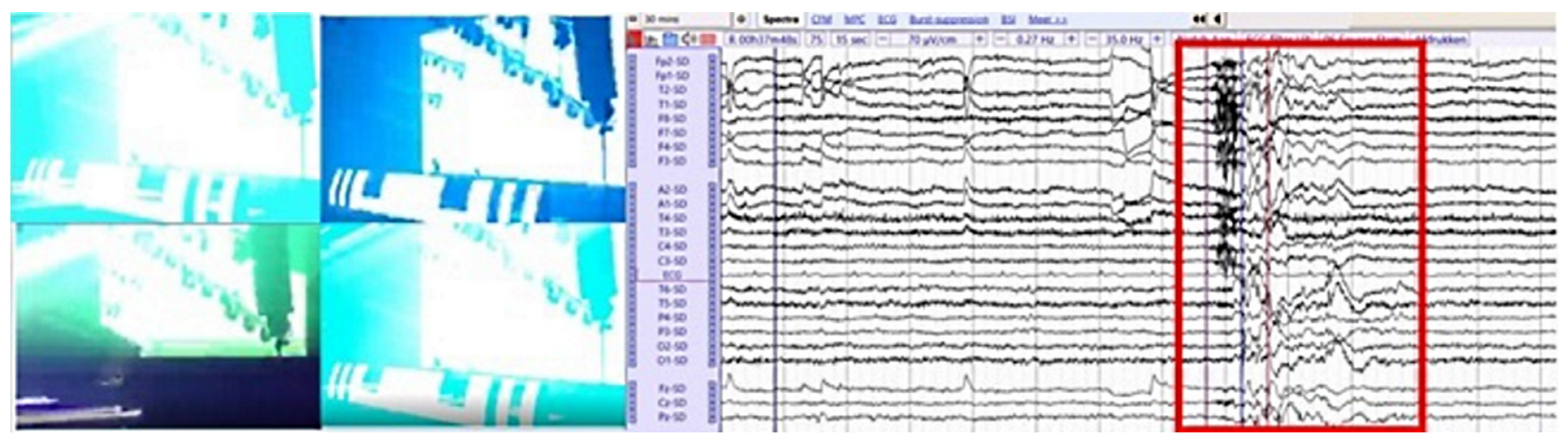

Figure 1 Electroencephalography test results while the patient is watching a video recording of the festival he attended. Abnormal brain activity is arced in red. 


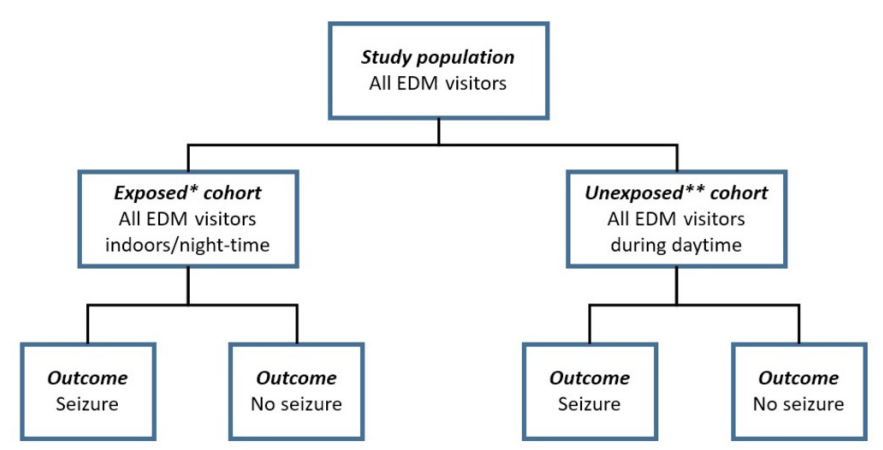

* Exposed is regarded as exposure to stroboscopic light effects in a light deprived environment ** Unexposed is regarded as exposure to stroboscopic light effects in a light environment

Figure 2 Summary of the study design, group distribution and outcome parameters. EDM, electronic dance music.

exact time and duration of the festivals, as well as visitor numbers, retrieved from online sources and the medical assistance companies' administration.

Relevant data were obtained from the source files of a large company which provides of medical assistance to more than $90 \%$ of such festivals in The Netherlands (Event Medical Services, Uden, The Netherlands). The company anonymously keeps track of all visitors receiving medical attention, registering the reason for medical consultation, gender, age and (self-)reported alcohol or drug use. In addition, general festivals characteristics, such as visitor numbers, are registered.

Apart from alcohol, ecstasy (more commonly referred to as 'XTC') is the most used recreational drug during EDM festivals. Although the literature is not unequivocal, the use of ecstasy can probably facilitate provocation of epileptic seizures. ${ }^{10}$ Data on use of ecstasy were therefore compared between both exposed versus unexposed individuals seeking medical attention.

After we ascertained that $28 \mathrm{EDM}$ festivals, with a total of 400343 spectators were present in the study cohort, we calculated the power of our sample size. The power to detect a twofold difference in the incidence density of epileptic seizures between exposed and unexposed individuals with $\alpha=0.05$ was $>90 \%$.

\section{Statistical methods}

The incidence density ratio (number of registered epileptic seizures per person-hour) was calculated to determine the risk of seizing in exposed versus unexposed individuals. The Fisher's Exact with mid-p test was used to determine statistical significance. Analysis for this study was performed using Statistical analysis was performed using SPSS V.22.0 (IBM Corporation).

\section{Patient and public involvement}

The case report described earlier was the inducement to this cohort study. All collected patient data in this study and original database were anonymous, and therefore no ethical approval to conduct this study was required.

\section{RESULTS}

\section{Participants}

The number of visitors of the $28 \mathrm{EDM}$ festivals included in the cohort was 400343 , representing a total of 4556556 person hours. Details are presented in table 1 . The cohort was divided into 241543 persons (representing 2222196 person hours) exposed (night-time/inside) and 158800 persons (representing 2334360 person hours) unexposed (daytime and outdoors).

During the festivals, medical assistance was provided 2776 times. The incidence density of medical assistances (expressed as number of calls per 10000 , standardised to 9 hours presence; the approximate average duration of a night-time EDM concert) was equally divided between exposed and unexposed groups.

\section{Epileptic seizures}

A total of 39 persons with seizures identified as epilepsy were registered, 30 of which occurred in the exposed group, versus 9 in the unexposed group. Table 2 shows the incidence densities for 10000 persons, standardised to 9 hours exposure. The incidence density ratio of seizures in exposed versus unexposed was 3.5 (95\% CI: 1.7 to $7.8 ; \mathrm{p}<0.0005)$.

\section{Ecstasy use}

Ecstasy use in the total group of individuals receiving medical assistance was 26\% (357/1379) in the exposed group, and 9.7\% (136/1397) in the unexposed group. However, the proportion of seizure cases with ecstasy use was similar among the exposed (8 out of $30 ; 27 \%$ ) and the unexposed (3 out of $9 ; 33 \%$ ).

\section{Table 1 Cohort characteristics}

\begin{tabular}{llll}
\hline & Exposed (darkness) & Unexposed (daylight) & Total \\
\hline Number of festivals & 21 & 7 & 28 \\
Average festival duration (hours) & 9.2 & 14.7 & 12.6 \\
Cumulative number of spectators & 241543 & 158800 & 400343 \\
Cumulative person hours & 2222196 & 2334360 & 4556556 \\
Number of medical assistances & 1379 & 1397 & 2776 \\
$\begin{array}{l}\text { Number of medical assistance/9Person hours. } \\
10^{4}\end{array}$ & 55.8 & 54.0 & 54.9 \\
\hline
\end{tabular}


Table 2 Seizures and substance abuse during EDM festivals

\begin{tabular}{llll}
\hline & $\begin{array}{l}\text { Exposed (indoor- night- } \\
\text { time) }\end{array}$ & Unexposed (daylight) & Total \\
\hline Registered unique* seizure episodes & 30 & 9 & 39 \\
\hline Seizures/9. $10^{4}$ person hours & $1.20 \dagger$ & 0.35 & 0.81 \\
Age of seizure cases (mean) & 22.3 & 24.5 & 22.8 \\
Male/female-ratio of seizure cases & 1.5 & 2.0 & 1.6 \\
\hline Ecstasy intoxication during seizure & $8(27 \%)$ & $3(33 \%)$ & $11(28 \%)$ \\
Ecstasy intoxications & 357 & 136 & 493 \\
\hline Ecstasy cases $/ 9.10^{4}$ person hours & 14.5 & 5.2 & 9.7 \\
\hline
\end{tabular}

*Multiple seizures within a short time span in one person are counted as a singular seizure episode.

$\dagger P<0.0005$ seizures $/ 9.10^{4}$ person hours exposed versus unexposed, by Fisher Exact mid-P test.

EDM, electronic dance music.

\section{DISCUSSION}

EDM concerts almost always use stroboscopic light effects. This study strongly suggests that such light effects markedly enhance the risk of epileptic seizures among visitors. Factors that may enhance the tendency to develop seizures may include age-related susceptibility, sleep deprivation and substance abuse, but these factors could largely be controlled for by including daylight concerts attracting a similar audience. However, given the available evidence, it was not possible to fully disentangle the individual components of epileptogenic circumstances, being stroboscopic light, sleep deprivation, high level of physical activity and, in some cases, stimulant use to a detailed extent.

Although our study is very large and, in our view, offers the best possible way of addressing the study question, some limitations intrinsic to its design should be mentioned. Given the anonymous nature of the database there was no possibility to adjust for the number of unique persons in the entire cohort. The same person may have visited multiple festivals. Theoretically, however unlikely, even registered seizure episodes may have been reoccurrences in the same individual at a different EDM festivals. Relevant medical history data or medication use may also have been missed in the data registration. For example, some patients with known (photosensitive) epilepsy may have been among the visitors and taken precautions against stroboscopic seizure induction, which may have created a bias. Individuals who know that they may have seizures are also less likely to consult medical staff than persons with a first seizure. Given this anonymous nature of the data, patient follow-up also was not a possibility.

Since we only had aggregate data of visitors of medical assistances, we cannot formally adjust for bias caused by, for example the use of ecstasy. Ecstasy as well as other stimulants are more commonly used at night-time festivals and may be an additional causal factor in the increased seizure incidence, although at common dosages of such substances for recreational use, seizure risk is, if anything, low. When dosages exceed the recreational dose however, seizures are seen more often, especially with psychostimulants like ecstasy. ${ }^{10-12}$ The fact that a minority of seizure patients in both exposed and unexposed people had signs of ecstasy intoxication also argues against substantial confounding. Sleep deprivation however is a clear factor in multiple forms of epilepsy, including photosensitive epilepsy. ${ }^{13}$ It is likely that attendees of isolated night events are more sleep deprived than during isolated day events. However, many EDM concerts are part of multiday events, during which visitors may be extremely sleep deprived. The number of EDM concerts taking place as part of a multiday event, or singularly taking place indoors during the daytime, could not be analysed separately, because seizure numbers for such events became too low to draw meaningful conclusions. Thus, stroboscopic light effects are prime suspects, but probably not solely responsible for the increased seizure risk during EDM concerts taking place in darkness. Another limitation is that our study relies on on-site assessment/witness reports of epileptic seizures. Although bystanders may give a fairly reliable account of what happened, both underdiagnosis and over diagnosis of epilepsy are possible. We think, however, that our numbers are probably an underestimation of the total of people who had epileptic seizures. Some, for example, may have recovered and chosen not to seek medical attention, and some may not have been recognised or appropriately documented as an epileptic seizure. Hence, the real incidence of epileptic seizures may in fact be higher than reported in this study.

Regardless of whether stroboscopic light effects are solely responsible, or whether sleep deprivation and/or substance abuse also play a role, the appropriate interpretation is that large EDM festivals, especially during night-time, probably cause at least a number of people per event to suffer epileptic seizures. Given the plausible role of stroboscopic light effects, attendants with a history of PSE should either avoid such festivals, or take proper precautions (informing their company/friends, avoiding sleep deprivation or stimulant abuse, taking a position remote from the stage, quickly leave to a location without light effects when experiencing aura(-like) symptoms and so on). Given the large dataset, we believe our findings are 
externally valid, at least for other EDM festivals in other countries, which generally attract a similar audience. Our results may be less applicable to other types of concerts or festivals, which use less stroboscopic lights and attract a different audience.

Acknowledgements We are indebted to Event Medical Services Inc. for allowing us access to their data files.

Contributors NS collected the data. NS and YMS drafted the manuscript and contributed to all other quality aspects of the study. CS and MV aided in the case report and EEG data processing. MV and CS performed critical revision of the manuscript. All authors read and approved the final manuscript.

Funding The authors have not declared a specific grant for this research from any funding agency in the public, commercial or not-for-profit sectors.

Competing interests None declared.

Patient consent for publication Obtained.

Provenance and peer review Not commissioned; externally peer reviewed.

Data sharing statement Due to the (commercially, ethically) sensitive nature of the data, the source did not consent in their data being retained or shared.

Open access This is an open access article distributed in accordance with the Creative Commons Attribution Non Commercial (CC BY-NC 4.0) license, which permits others to distribute, remix, adapt, build upon this work non-commercially, and license their derivative works on different terms, provided the original work is properly cited, appropriate credit is given, any changes made indicated, and the use is non-commercial. See: http://creativecommons.org/licenses/by-nc/4.0/.

\section{REFERENCES}

1. EVAR advisory services. The economic significance of EDM for the Netherlands, 2012.

2. Anyanwu EC, Ehiri JE, Jones J. Photosensitive epilepsy beyond adolescence: is freedom from photosensitivity age-dependent? Int $J$ Adolesc Med Health 2003;15:125-32.

3. Parra J, Kalitzin SN, Lopes da Silva FH. Photosensitivity and visually induced seizures. Curr Opin Neurol 2005;18:155-9.

4. Takada H, Aso K, Watanabe K, et al. Epileptic seizures induced by animated cartoon, "Pocket Monster". Epilepsia 1999;40:997-1002.

5. Wilkins AJ, Bonanni P, Porciatti V, et al. Physiology of human photosensitivity. Epilepsia 2004;45(Suppl 1):7-13.

6. Quirk JA, Fish DR, Smith SJ, et al. Incidence of photosensitive epilepsy: a prospective national study. Electroencephalogr Clin Neurophysiol 1995;95:260-7.

7. Verrotti A, Beccaria F, Fiori F, et al. Photosensitivity: epidemiology, genetics, clinical manifestations, assessment, and management. Epileptic Disord 2012;14:349-62.

8. Dugan P, Carlson C, Bluvstein J, et al. Auras in generalized epilepsy. Neurology 2014;83:1444-9.

9. von Elm E, Altman DG, Egger M, et al. The Strengthening the Reporting of Observational Studies in Epidemiology (STROBE) Statement: guidelines for reporting observational studies. Int J Surg 2014;12:1495-9.

10. Berman S, O'Neill J, Fears S, et al. Abuse of amphetamines and structural abnormalities in the brain. Ann N Y Acad Sci 2008;1141:195-220.

11. Zagnoni PG, Albano C. Psychostimulants and epilepsy. Epilepsia 2002;43(Suppl 2):28-31.

12. Kalant $\mathrm{H}$. The pharmacology and toxicology of "ecstasy" (MDMA) and related drugs. CMAJ 2001;165:917-28.

13. Malow BA. Sleep deprivation and epilepsy. Epilepsy Curr 2004:4:193-5. 